\title{
A ABORDAGEM DIREITO E POLÍTICAS PÚBLICAS COMO FERRAMENTA DE APRIMORAMENTO DAS INSTITUIÇÕES JURÍDICAS: QUALIDADE ORGANIZACIONAL, SISTEMATIZAÇÃO DE DADOS E FOMENTO DAS RELAÇÕES INTERINSTITUCIONAIS
}

\section{THE LAW AND PUBLIC POLICY APPROACH AS A TOOL FOR THE IMPROVEMENT OF LEGAL INSTITUTIONS: ORGANIZATIONAL QUALITY, DATA SYSTEMATIZATION AND THE IMPROVEMENT OF INTERINSTITUTIONAL RELATIONS}

PATRICIA Ulson PIZARRO WERNER ${ }^{1}$

\begin{abstract}
Resumo: A abordagem Direito e Políticas Públicas (DPP) é uma ferramenta que pode contribuir de forma importante para o aperfeiçoamento global da atuação das Instituições Jurídicas. Os desafios interpretativos impostos para concretização de direitos, em especial, os direitos fundamentais, somados aos estruturais de cada organização, revelam a necessidade de compreensão dos problemas de forma interdisciplinar. A partir dessa premissa, o artigo tem como proposta a análise de três enfoques que visam contribuir para a evolução da construção das estruturas metodológicas e aplicações concretas da abordagem DPP: (i) Cooperar para a elaboração do diagnóstico do perfil institucional, dos indicadores para melhorias de fluxos, criação/reformulação de planos de capacitação profissionais e refinamento do controle interno; (ii) Criar espaço para a organização de informações exclusivas, inerentes à missão constitucional de cada Instituição, com o fim de ofertar publicamente um banco de dados sistematizado para constante avaliação das políticas públicas; (iii) Fomentar a abertura do dialogo interinstitucional. Ao final, para melhor compreensão do tema, será apresentada para análise crítica a experiência pragmática de construção da política pública educacional para alunos com deficiência no Estado de São Paulo, nos anos de 2016 e 2017.
\end{abstract}

Palavras-Chave: Políticas Públicas; Instituições Jurídicas; Organização de dados; Diálogo interinstitutional.

\footnotetext{
${ }^{1}$ Procuradora do Estado de São Paulo. Mestre e Doutora em Direito Constitucional pela PUC/SP (Brasil). Contato: patriciapwerner@gmail.com. CV: http://lattes.cnpq.br/8450535636953934
} 
AbStRact: The Law and Public Policy (LPP) approach is a valuable tool which contributes directly to the overall performance improvement of legal institutions. The interpretative challenges imposed for the concretization of rights, in particular, the fundamental rights, added to the institutional powers of each organization, reveal the necessity of comprehending these problems in an interdisciplinary way. From this premise, the article proposes the analysis of three approaches, which aim to contribute towards the evolution of structures, methodologies and concrete applications of the DPP approach: (i) to cooperate in making the diagnosis of the institutional profile, of the indicators for flow improvements, creation/redesign of professional training plans, and refinement of internal control; (ii) Create a space for the systematized organization of private information, inherent to the constitutional mission of each institution, with the goal of offering an organized public database for the constant evaluation of public policies; (iii) Encourage interinstitutional dialogue. Finally, for a better understanding of the proposal, the practical experience of building the educational public policy for students with disabilities in the State of São Paulo, from 2016 and 2017, will be presented for critical analysis.

KeYWORDS: Public Policies; Legal Institutions; Data organization; Interinstitucional dialogue.

\section{ABORDAGEM DPP: CONCEITOS ESSENCIAIS E DELIMITAÇÃO DA PROPOSTA DO PRESENTE ESTUDO}

As reflexões que serão apresentadas a seguir visam contribuir com a evolução da construção das estruturas metodológicas específicas e aplicações concretas da abordagem Direito e Políticas Públicas (DPP).

O campo de análise será restrito às Instituições Jurídicas, recorte epistêmico necessário diante da amplitude do tema, escolhido justamente por ser um profícuo espaço para o desenvolvimento de pesquisas acadêmicas que ajudarão a traçar diretrizes para aperfeiçoar as Instituições internamente e, ao mesmo tempo, servirá como objeto para aprimorar o método de abordagem DPP.

$\mathrm{O}$ conceito de Instituições Jurídicas será utilizado de forma ampla², considerando que a proposta do Grupo de Pesquisa Estado, Direito e Políticas

\footnotetext{
2 Instituição no sentido apontado por Santi Romano (1977, p. 104-106), "que tem características, estruturas e finalidades variadas [...] contempladas pelo direito do Estado, e assumem, baseadas no direito estatal, diversos aspectos e figuras [...]". Também no sentido de aproximação dos três
} 
Públicas, materializada neste dossiê, foi justamente a de fixar diretrizes gerais que possam ser replicadas e compartilhadas (BUCCI, 2019), por exemplo, entre diversos atores jurídicos, como a Magistratura, o Ministério Público, a Defensoria Pública, a Advocacia Pública, Polícia Judiciária, a Ordem dos Advogados do Brasil, dentre outras. Particularmente, ressalto que a visão exposta a seguir revela a précompreensão do tema a partir da minha experiência profissional como Procuradora do Estado de São Paulo, nas áreas do contencioso, da consultoria e da gestão administrativa.

A proposta parte das lições de Maria Paula Dallari Bucci (2002, p. 249) e encontra suporte em alguns conceitos que serão a base do presente trabalho, em especial: (i) o conhecimento com profundidade do objeto da política pública aumenta a possibilidade de efetividade do programa de ação governamental; (ii) o sucesso da política pública está relacionado à qualidade do processo administrativo que a precede e de quem a implanta, com ênfase nas "informações sobre a realidade a transformar, a capacitação técnica e a vinculação profissional dos servidores públicos, a disciplina dos serviços públicos" (BUCCI, 2002, p. 269); (iii) entende-se por metodologia jurídica das políticas públicas "a tarefa de descrever, compreender e analisar as políticas públicas, de modo a conceber as formas e processos jurídicos correspondentes (BUCCI, 2006, p. 47); (iv) a abordagem DPP permite compreender o direito "em ação" nas políticas públicas, superando a abordagem meramente descritiva, estática e formal do elemento jurídico e, por conta disso, não o isolando ou dissecando do contexto políticoinstitucional em que opera; em suma, integrando os juristas no campo multidisciplinar de estudo das políticas públicas (BUCCI, 2017, p. 315); e (v) a ideia de arranjo institucional como um "agregado de disposições, medidas e iniciativas em torno da ação governamental, em sua expressão exterior, com um sentido sistemático" considerando que a política pública "é necessariamente a composição de um conjunto de elementos, normas, órgãos, valores, interesses, orientado à implementação de uma mudança estratégica "(BUCCI, 2013, p. 205-234).

\section{A APLICAÇ̃̃o DA ABORDAGEM DPP PARA APRIMORAR AS INSTITUIÇÕES JURÍDICAS}

A seguir serão apresentadas propostas de aplicação da abordagem DPP para o aperfeiçoamento das Instituições Jurídicas sob três enfoques: (i) Cooperar para a elaboração do diagnóstico do perfil institucional, de indicadores para melhorias de fluxos, criação/reformulação de planos de capacitação profissionais e refinamento do controle interno, incluindo a ideia de boas práticas e processos de accountability; (ii) Criar espaço para organização de informações exclusivas, inerentes à missão

planos de análise do fenômeno governamental: macro, micro e mesoinstitucional e, por outro lado, a expressão exterior da política pública como arranjo institucional, nos termos fixados por Bucci (2013, p. 205-234). 
constitucional de cada Instituição, com o fim de ofertar publicamente um banco de dados sistematizado para constante avaliação das políticas públicas; (iii) Fomentar a abertura do dialogo interinstitucional com foco em resultados.

\section{Capacidade de auto-organização estrutural: perfil institucional, controle interno, boas práticas, optimização de fluxos e eficiência}

A abordagem DPP serve como linha mestra para que cada Instituição Jurídica possa fazer um trabalho constante de autoconhecimento e avaliação do desempenho no cumprimento de sua missão constitucional. Em termos práticos, trata-se de estabelecer o diagnóstico individualizado de cada política pública desenvolvida com o fim de compor uma nova agenda de governança proativa, ou seja, assentar um ciclo de práticas institucionais virtuosas, nas esferas preventiva, repressiva e de assessoramento.

Parte-se da premissa de que as regras estruturais de cada Instituição influenciam diretamente a produção das políticas públicas, ou seja, é "uma força relevante, que vai além dos indivíduos e grupos que as compõem" (SOUZA, 2006, p. 20-45) .

O controle interno pode ser compreendido como a responsabilidade da Instituição executora pela sua própria administração, a autotutela (ARAÚJO, 2009, p. 1050-1151), com o fim de identificar um quadro real das políticas públicas desenvolvidas e avaliar a composição do binômio eficácia e eficiência, sendo a primeira a vedação de descumprir objetivos e metas constitucionais e, a segunda, a proporcionalidade material entre fins e os meios, o que implica na análise do custo social e da repercussão sobre a formação de uma consciência de ação coletiva, de interesse público (BUCCI, 2002, p. 183), assim como, ganha relevo a economicidade, a qual veda o desperdício (FREITAS, 2013, p. 110-111).

A partir da constatação desse panorama, passa a ser possível detectar ações positivas que devem ser preservadas, e pontos negativos, como lacunas/omissões, obstáculos, fraudes, visando justamente estabelecer uma visão clara para correção de fluxos e revisão de metas.

Nesse compasso, evidencia-se a importância de investir no desenvolvimento de um novo olhar para o problema, no sentido utilizado por Bucci e Coutinho (2017, p. 316), a partir da abordagem DPP, ou seja, é necessário analisar os arranjos jurídico-institucionais como expressões particulares da organização da ação governamental, "sem perder de vista os fins, essa abordagem supõe que alcançá-

\footnotetext{
${ }^{3}$ Segundo a autora, "Em geral, instituições são associadas a inércia, mas muita política pública é formulada e implementada. Assim, o que a teoria neo-institucionalista nos ilumina é no entendimento de que não são só os indivíduos ou grupos que têm força relevante influenciam as políticas públicas, mas também as regras formais e informais que regem as instituições".
} 
los depende da existência de meios cujas engrenagens são, também elas, em larga e crucial medida, jurídicas".

A abordagem DPP ganha a perspectiva de uma plataforma na qual convergem várias iniciativas necessárias para a resolução de problemas, incluindo a automação e optimização de fluxos, como por exemplo: (i) a criação e aperfeiçoamento da informatização do processo administrativo e judicial; (ii) a redução do número de procedimentos burocráticos procrastinadores; (iii) com consequente impacto na qualidade e especialização da área de recursos humanos; (iv) recuperação e sistematização de informações, processamento e armazenamento de dados; (iv) possibilita que as informações geradas sejam disponibilizadas de forma organizada e acessível, de modo a atender ao direito fundamental constitucional e à regulamentação categorizada na Lei de Acesso de Informações ${ }^{4}$.

Possibilita ainda o aprimoramento do sistema de informações contábeis institucional para embasar a fase da tomada de decisões, aumenta a transparência do processo de prestações de contas, instrumentaliza o controle social, com ênfase na avaliação dos resultados obtidos em relação à economicidade, eficiência, eficácia e efetividade. Esta percepção preconiza os ideais da contabilidade aplicada ao setor público, que tem por foco a proteção do erário, ao disponibilizar aos usuários informações sobre os resultados alcançados e os aspectos de natureza orçamentária, econômica, financeira e física do patrimônio da entidade do setor público e as suas mutações ${ }^{5}$.

A concepção da necessidade de consolidar a informação sobre o patrimônio público encontra ainda guarida na responsabilidade na gestão fiscal, que pressupõe a ação planejada e transparente para a manutenção do equilíbrio das contas públicas ${ }^{6}$.

Somente com um controle interno das estruturas institucionais efetivo será possível dar cumprimento aos ditames legais, prevenir e punir práticas de atos de improbidade administrativa ${ }^{7}$, que resultem em enriquecimento ilícito, causem prejuízo ao erário, atentam contra os princípios da Administração Pública, além da prática da corrupção ${ }^{8}$ e crimes contra a Administração Pública.

Há legislação complexa tentando prevenir os problemas, como o Código de Conduta da Alta Administração Federal, Código de Ética Profissional do Servidor Público Civil do Poder Executivo Federal' ${ }^{9}$, Ouvidorias, Controladorias, Comissões

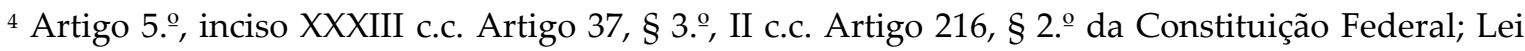
Federal n. ${ }^{\circ}$ 12.527/2011.

${ }^{5}$ Contabilidade Aplicada ao Setor Público é o ramo da ciência contábil que aplica, no processo gerador de informações, os Princípios de Contabilidade e as normas contábeis direcionados ao controle patrimonial de entidades do setor público. (Redação dada pela Resolução CFC no . 1.437/13).

${ }^{6}$ Lei de Responsabilidade Fiscal, Lei Complementar n.․ 101/2000.

${ }^{7}$ Lei Federal n. ${ }^{\circ}$ 8.429/92.

${ }^{8}$ Lei Federal n..$^{\circ}$ 12.846/13.

${ }^{9}$ Decreto Federal n. ${ }^{\circ}$ 1.171/94.
} 
de Ética, definições de incompatibilidades, monitoramento da avaliação patrimonial, porém, o desafio é justamente conseguir implantar na estrutura administrativa esses valores éticos de forma constante e punir de forma efetiva o desvio de conduta com celeridade. Aqui, a abordagem DPP é um instrumento essencial por possibilitar detectar as deficiências na organização institucional, no sentido de dar mais abrangência ou profundidade à aplicação dos instrumentos de controle a partir de uma visão mais ampla da política pública em análise, os atores, os interesses em jogo, enfim uma visão-quadro do problema (policy making).

No âmbito das instituições jurídicas há o dever de exercer esse controle interno e assegurar o respeito aos princípios impostos pelo ordenamento jurídico, razão pela qual a organização dos dados e metas de forma transparente vai possibilitar, além aprimoramento da execução da missão legal, a abertura do diálogo interinstitucional e, também, o controle por parte do cidadão, nos termos fixados pela Constituição Federal ${ }^{10}$.

Será também uma importante ferramenta para o aprimoramento do Sistema de Controle Interno, estabelecido pelo artigo 74 , incisos I a IV e $\S 1 .^{\circ}$ da Constituição Federal ${ }^{11}$, que inova ao estabelecer a necessária integração dos Poderes Legislativo, Executivo e Judiciário, conforme ensina Maria Sylvia Zanella Di Pietro:

O artigo 74 da Constituição inova de várias maneiras: primeiro, ao deixar claro que cada um dos Poderes terá um sistema de controle interno; segundo, ao prever que esse sistema se exercerá de forma integrada entre os três Poderes; terceiro, ao estabelecer a responsabilidade solidária dos responsáveis pelo controle quando, ao tomarem conhecimento de irregularidade, deixarem de dar ciência ao Tribunal de Contas $\left(\$ 1 .{ }^{\circ}\right)$; finalmente, ao colocar o

\footnotetext{
${ }^{10}$ Conforme prevê o art. 37, caput e $\S 3 .{ }^{\circ}$, incisos I a III: $\S 3^{\circ}$ A lei disciplinará as formas de participação do usuário na administração pública direta e indireta, regulando especialmente: I - as reclamações relativas à prestação dos serviços públicos em geral, asseguradas a manutenção de serviços de atendimento ao usuário e a avaliação periódica, externa e interna, da qualidade dos serviços; II o acesso dos usuários a registros administrativos e a informações sobre atos de governo, observado o disposto no art. $5^{\circ}$, X e XXXIII; III - a disciplina da representação contra o exercício negligente ou abusivo de cargo, emprego ou função na administração pública.

${ }^{11}$ I - avaliar o cumprimento das metas previstas no plano plurianual, a execução dos programas de governo e dos orçamentos da União; II - comprovar a legalidade e avaliar os resultados, quanto à eficácia e eficiência, da gestão orçamentária, financeira e patrimonial nos órgãos e entidades da administração federal, bem como da aplicação de recursos públicos por entidades de direito privado; III - exercer o controle das operações de crédito, avais e garantias, bem como dos direitos e haveres da União; IV - apoiar o controle externo no exercício de sua missão institucional. $\S 1^{\circ}$ Os responsáveis pelo controle interno, ao tomarem conhecimento de qualquer irregularidade ou ilegalidade, dela darão ciência ao Tribunal de Contas da União, sob pena de responsabilidade solidária.
} 
Tribunal de Contas como uma espécie de ouvidor-geral a quem os cidadãos, partidos políticos, associações ou sindicatos podem denunciar irregularidades ou ilegalidades $\left(\S 2 .{ }^{\circ}\right)$. (DI PIETRO, 2017, p. 909)

A abordagem DPP ao estruturar a visão do problema de modo a conectar atores, ideias e instituições, a partir do ciclo das políticas públicas ${ }^{12}$, fornece base para a criação do Manual de Boas Práticas, com o estabelecimento de códigos de condutas esperados, serve como suporte na composição da estrutura do accountability através do aumento da eficiência (fluxos) e revisão de condutas éticas, incluindo o aprimoramento da relação hierárquica, qualidade técnica da equipe, renovação da estrutura tecnológica e eficiência orçamentária/financeira - nas esferas preventiva, repressiva e de assessoramento.

\section{Tecnologia aplicada à abordagem DPP: o valor de um banco de dados sistematizado e a credibilidade do manejo das redes de informação}

As Instituições Jurídicas geram e armazenam dados exclusivos, originários da missão legal de cada uma, que em regra, acabam não sendo ordenados e utilizados para gerarem plataformas estruturais de diretrizes, seja para o aperfeiçoamento do controle interno, seja para divulgação e transparência de suas ações.

A abordagem DPP passa a ser um instrumento eficaz para, além de auxiliar na boa-gestão e a evolução das políticas públicas (feedback), conforme abordado no item anterior, possibilitar a sistematização de forma lógica das informações e fluxos.

Demonstra a importância da inovação tecnológica para a produção e organização de dados, considerando ainda a dificuldade na classificação e os limites tênues que devem ser observados para a garantia dos direitos envolvidos, afinal, alguns dados devem ser disponibilizados para fomentar a pesquisa científica e a exercício da cidadania, outros, devem ser sigilosos para a garantia de outros direitos fundamentais.

A organização racional dos dados possibilita a avaliação inicial das opções políticas existentes, identificação e análise de soluções possíveis, para que a Administração possa fundamentar a tomada de decisões. A fase de formulação ou reformulação da política pública é considerada "um processo altamente difuso e desconexo" (HOWLETT; RAMESH, 2013, p. 124), motivo pelo qual é importante compreender que a organização de dados confiáveis é um instrumento fundamental desse processo (policy-making) com o fim de gerar decisões consensuais e tendentes ao êxito.

\footnotetext{
12 Adota-se o conceito de Howlett e Ramesh (2013). O ciclo compreende cinco fases: montagem da agenda, formulação de políticas: instrumentos e design, tomada da decisão política. implementação de políticas e avaliação de politicas. Tema tratado no artigo Werner (2019).
} 
Também será o pilar para a definição de estratégias e escolhas dos instrumentos disponíveis para que os governos façam suas opções. A abordagem DPP, nesse contexto, auxilia na criação de um quadro real do problema a ser enfrentado e, consequentemente, na escolha dos instrumentos políticos que podem ser $\operatorname{adotados}^{13}$. Destaca-se aqui a ideia de buscar o alinhamento da linguagem entre áreas diversas sobre determinado assunto, como por exemplo, o projeto de taxonomia da educação que visa sistematizar a sua linguagem, multidisciplinar e diversa, encabeçado pelo Instituto Articule (SEM AUTOR, 2019), com o fim de monitorar a judicialização sobe o tema.

Nesse profícuo campo de estudo das classificações dos instrumentos políticos existentes para a formulação das políticas públicas, destaca-se a tese de Christopher Hood (1983), que sugere ter o governo quatro instrumentos sociais disponíveis a serem utilizados para incentivar ou não o processo de formulação das políticas públicas. Assim, o autor identificou classes de instrumentos que podem ser utilizados como ferramentas para atingir os fins do governo, denominada em inglês "Modelo NATO", que busca organizar quatro categorias amplas de instrumentos: Nodalidade (nodality), Autoridade (authority), Tesouro/orçamento (treasure); Organização (organization).

Em breves linhas, as categorias buscam sistematizar a importância do uso da informação disponível para o governo/administração. A noção de "nodalidade" representa a capacidade do governo em centralizar e coordenador redes de informação (networks), revela a importância do manejo das informações em seu poder sobre os atores políticos centrais. Autoridade é a categoria que representa a capacidade da administração no uso das competências legais (administrative power). Tesouro representa a consistência das informações orçamentárias e financeiras. Organização é conhecer as habilidades das pessoas que vivem na sociedade, prédios, materiais, equipamentos e demais arranjos, assim, mapear as instituições e o perfil das pessoas que às compõem que estão à sua disposição.

Dessa forma, entende-se que o governo precisa conhecer a sua capacidade administrativa (authoritative strategy), investir na formação de uma rede de informações próprias, que sejam filtradas e trabalhadas de forma eficaz de modo a criar um ponto de convergência de análise, ponto nodal, no sentido concentrar informações para coletar informações (detectors) e para influenciar o comportamento da sociedade (effectors), v.g., na área da saúde, as políticas públicas de vacinação, que podem ter início com caráter preventivo ou a partir da informação da ocorrência de um surto, fato que gera uma campanha pública de informação e criação de postos de vacinação.

13 A variedade de instrumentos disponíveis aos policy-makers é limitada apenas por sua imaginação. Entretanto, os scholars fizeram inúmeras tentativas para identificar esses instrumentos e classificá-los em categorias de importância [...]. (HOWLETT, 2013, p. 128). 
Nesse cenário, é importante notar que a tese também prevê limites, a nodalidade tem o limite na credibilidade do manejo das informações, a autoridade na própria estrutura legal, o tesouro na capacidade financeira e a organização na capacidade de suas estruturas.

A conjugação desses quatro campos demonstra a capacidade do autogoverno (own administrative capacity), que inclui a habilidade de construir estratégias, de desenhar as instituições como representativas dos interesses sociais e conseguir estabelecer o diálogo efetivo e coordenar as diversas políticas públicas. O valor da informação faz com que os instrumentos organizacionais sejam bem utilizados, coordenados entre os diversos atores envolvidos, de modo a proporcionar um ciclo de compreensão, aprendizado e eleição de políticas públicas referencias.

\section{Abertura do diálogo interinstitucional: arranjos jurídico-institucionais}

As Instituições devem organizar-se para cumprir a sua missão e, ao mesmo tempo, abrir espaços para estabelecer diálogos interinstitucionais, em especial, quando se detectam dificuldades como a judicialização, problemas de repartição de competência, necessidade de ação conjunta com outras instituições, em especial, na resolução de direitos complexos, como os fundamentais sociais, que necessitam da atuação integrada de várias áreas do governo.

Nesse ponto, destaca-se a ideia da importância da formação de rede de atores que detém a capacidade compreender o problema, conhecer a legislação, construir estratégias, encontrar instrumentos para solução. Aqui está a importância do DPP como um método para subsidiar escolhas e, principalmente, modelagens jurídicas possíveis, como atingir o objetivo fixado de forma eficaz, dentro dos parâmetros legais.

A estruturação clara e fundamentada da política pública possibilita também a qualidade da atuação do controle externo, do controle jurisdicional e do controle social.

Aqui, é interessante lembrar a concepção do "dever da boa Administração", derivada do Princípio do Interesse Público, ou seja, a ideia de que a atividade administrativa "deve traduzir-se em actos cujo conteúdo seja também inspirado pela necessidade de satisfazer de forma mais expedita e racional possível o interesse público constitucional e legalmente fixado" (AMARAL, 2001, p. 38).

Para tanto é essencial compreender o problema globalmente em todos os seus planos: macroinstitucional, com foco na ação governamental; microinstitucional, com atenção na ação governamental em torno da qual se movem os agentes públicos e privados e mesoinstitucional, no qual os arranjos institucionais ocorrem ${ }^{14}$, percepções somadas que impulsionam o diálogo interinstitucional.

14 Síntese da ideia desenvolvida na obra de Bucci (2013). 


\section{UMA EXPERIÊNCIA ILUSTRATIVA DA APLICAÇÃO DA ABORDAGEM DPP: O

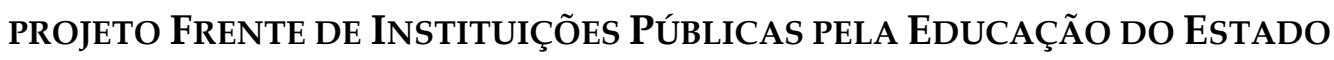 De SÃo Paulo (FIPESP)}

Um exemplo significativo para ilustrar a teoria exposta é o Projeto FIPESP desenvolvido no âmbito da Secretária de Estado da Educação do Estado de São Paulo.

A Frente de Instituições Públicas pela Educação do Estado de São Paulo (FIPESP) foi criada pela Resolução da Secretária da Educação SE 30, de 9 de maio de 2016 ${ }^{15}$, com fundamento na Meta 19 estabelecida pelo Plano Nacional de Educação (PNE), aprovado pela Lei federal n.. 13.005/14, no sentido de dar "a efetivação da gestão democrática da educação, associada a critérios técnicos de mérito e desempenho e à consulta pública à comunidade escolar, no âmbito das escolas públicas".

O direito à educação é classificado constitucionalmente como um direito fundamental social, expressamente reconhecido como um direito público subjetivo, a ser garantido pela família, Estado e sociedade, de modo a proporcionar políticas públicas articuladas, visando à formação geral dos educandos e sua inserção no mundo do trabalho ${ }^{16}$.

A ideia da gestão democrática encontrou guarida nos princípios do planejamento, controle, transparência e responsabilização, a partir da consolidação de mecanismos de planejamento educacional participativo que garantam o diálogo permanente entre todos os agentes do processo de ensino e aprendizagem.

Registro que no momento de elaboração da FIPESP não havia ainda sido aprovado o Plano Estadual de Educação, o qual foi concretizado através da aprovação da Lei Estadual n.o 16.279/2016, de 8 de julho de 2016, mas a ideia de gestão democrática foi devidamente incorporada na legislação.

O objetivo central da FIPESP foi estimular o desenvolvimento de estudos e debates acerca da condução de ações educacionais, visando ao pleno desenvolvimento das potencialidades dos educandos do sistema estadual de ensino através da promoção de audiências públicas e encontros com estudantes, pais ou responsáveis, profissionais de educação e comunidade escolar, visando o envolvimento de todos na organização curricular e na elaboração do projeto político pedagógico da escola.

Estruturalmente era presidida pelo titular da Pasta da Educação e contava com um integrante de cada uma das Instituição do Estado de São Paulo a seguir relacionadas: Poder Judiciário (Tribunal de Justiça), Ministério Público, Defensoria

\footnotetext{
15 Publicado no DOE de 10.5.16.

16 Artigo 6. o caput c.c. artigo 208, §1. da Constituição Federal. Para saber mais, Werner (2017).
} 
Pública, Procuradoria Geral do Estado, Assembleia Legislativa e Ordem dos Advogados do Brasil, seção São Paulo ${ }^{17}$.

As reuniões eram realizadas na sede da Secretária da Educação, com previsão de reuniões ordinárias quinzenais e, conforme o tema e atores envolvidos, eram realizadas reuniões extraordinárias.

A ideia foi crítica justamente por reunir somente Instituições da área jurídica ${ }^{18}$, o que levou ao questionamento do aspecto democrático de um grupo restrito, com exclusão da comunidade escolar em seu sentido estrito (FREITAS, 2016).

Porém, a maturidade e compromisso dos membros fez com o que o projeto produzisse um diálogo frutífero. Na realidade, a partir da eleição de certas políticas públicas fortemente judicializadas, optou-se por fazer reuniões temáticas, com convidados especialistas e técnicos, justamente para que se pudesse compreender o problema a partir de vários ângulos, com foco no estabelecimento de uma linguagem comum, considerando que a educação é uma área multidisciplinar.

A partir da compreensão da cada política em sua integralidade, de forma interdisciplinar, cada Membro da FIPESP era responsável por criar um canal de comunicação e compartilhar com a sua Instituição o quadro geral exposto, com foco nos gargalhos reais existentes, para que livremente cada uma fixasse parâmetros de como agir dentro da sua missão, com responsabilidade para ajudar a efetivamente solucionar o problema posto.

Assim, foram debatidas questões como a logística da merenda escolar, transporte escolar, inclusão de alunos com deficiência, dentre outras.

Estabeleceu-se um diálogo produtivo que buscou construir soluções consensuais, a partir da exposição da clara realidade sobre cada problema.

A abordagem DPP, nesse contexto, ajudou a dimensionar os efeitos na esfera administrativa das inúmeras ações judiciais coletivas e individuais. Afinal, o impacto de cada decisão judicial na área da educação reflete a realidade da rede estadual paulista de ensino. Somente a política pública para inclusão da pessoa com deficiência tinha à época cerca de 63 mil alunos. O grande fluxo de judicialização do tema, seja para matrícula em escolas especializadas, seja para transporte personalizado, a um custo muito alto, fez com que o tema fosse eleito como prioritário (SÃO PAULO, 2016).

A agenda central do grupo foi construir uma política pública que regulamentasse a inclusão dos alunos com deficiência, até então inexistente na Pasta formalmente. Ficou constatado um perigo comum com a judicialização dos

\footnotetext{
${ }_{17}$ Criado na gestão do Secretário da Educação Dr. Renato Nalini, composto por Wilson Levy Braga da Silva Neto (SEE), Patricia Ulson Pizarro Werner (PGE), Antônio Carlos Ozório Nunes (MP), Antônio Carlos Malheiros (PJ), Fátima Mônica Bragante Dinardi (PL), Rosa Ramos, Renata Flores Tibyriça (OAB); Renata Hauenstein, Raquel Fernanda Fávero e Ana Carolina Ferreira de Souza (SES).

18 Para aprofundar o tema, ver Gomes (2017).
} 
temas, o fato de a Administração passar a cumprir decisões judiciais, sem se organizar para efetivamente garantir o direito fundamental de forma sistematizada, eficiente e econômica.

A falta de uma política pública estruturada levava a falhas primárias, como a não formalização da matrícula regular de todos os alunos com deficiência; cumpriase a liminar, mas não havia o registro do aluno no sistema (RA), o que impactava diretamente nas estatísticas realizadas. Por outro lado, no momento da matrícula, não havia um procedimento para que os pais informassem sobre a situação do filho, e assim a Administração encaminhasse de forma célere o caso para a equipe multidisciplinar de avaliação pedagógica recomendar o melhor plano pedagógico para cada caso, assim como, no sítio eletrônico da Pasta não havia informações seguras sobre as regras gerais para efetivar a matrícula do aluno com deficiência, o que prejudicava a comunidade escolar em geral e a atuação das próprias Instituições Jurídicas, por exemplo, no momento de cobrar uma ação estatal com qualidade.

A construção da política pública levou mais de um ano, com uma série de reuniões com técnicos de várias áreas e a equipe do Gabinete da Pasta envolvida diretamente na questão, pois além de compreender como garantir o direito fundamental à educação, que não se confunde com o direito à saúde, nem assistencial à pessoa com deficiência, ponto nevrálgico muito complexo, há um sério problema de limites orçamentários e a real falta de profissionais habilitados para atender a uma demanda tão grande.

Nota-se que o grupo se reuniu para compartilhar visões próprias institucionais e para aprender com técnicos especializados em diversas áreas, incluindo a condução dos temas pela Coordenadoria Pedagógica da Pasta em todos os momentos.

Afinal, foi publicada formalmente pela Secretária Estadual da Educação a Resolução SES n.o 68, de 12/12/2017, que tem muito valor, por representar um paradigma para execução e avaliação da política pública inclusiva do aluno da rede pública com deficiência ${ }^{19}$. Foi o documento possível naquele momento, que necessita de monitoramento das metas fixadas e aprimoramento em vários pontos, como aperfeiçoar o atendimento aos alunos com transtorno do espectro autista,

\footnotetext{
19 Renata Flores Tibyriçá, Coordenadora do Núcleo dos Direitos do Idoso e da Pessoa com Deficiência da Defensoria Pública do Estado de São Paulo, a reunião busca determinar o apoio das instituições e da secretaria para que todas as pessoas com deficiência estejam, de fato, incluídas. “Nunca houve uma preocupação tão determinada de poder se debruçar de forma aprofundada a respeito desta questão. O objetivo é fazer com que os alunos da escola pública cheguem às escolas em situação de verdadeira inclusão". (SÃO PAULO, 2016).
} 
mas que passa a ser um referencial no ordenamento jurídico para efetivar os direitos envolvidos, seja pela via administrativa, seja pela via judicial. ${ }^{20}$

É interessante constatar o quanto é importante para dar efetividade ao direito fundamental à educação uma política pública formalizada de forma técnica e jurídica, ponto que corrobora a tese de Bucci e Coutinho de que:

a lente analítica de DPP dá mais atenção para as normas infralegais, como os decretos, portarias e os regulamentos, em razão do seu papel no preenchimento dos procedimentos e rotinas que definem, na ponta do processo, o funcionamento último das disposições mais abstratas dos comandos constitucionais e legais. Tais normas, longe de serem de relevância menor se comparadas às grandes diretrizes e comandos programáticos, são, elas próprias, a substância de que são feitas, quotidianamente, as políticas públicas. Por isso, também, essa abordagem enfatiza o olhar prospectivo e estratégico associado à construção dos arranjos jurídicoinstitucionais. (BUCCI, 2017, p. 316)

A experiência relatada serve como parâmetro para compreender a importância de estabelecer uma política pública organizada para aprimorar a qualidade da educação a partir do retrato real estatístico do número de alunos, desafios pedagógicos a serem enfrentados, limites orçamentários, assim como fixar parâmetros a serem utilizados pelas demais Instituições no exercício de suas missões constitucionais, como o Poder Judiciário, Poder Legislativo, Ministério Público, Defensoria Pública, Ordem dos Advogados do Brasil, organizações sociais, comunidade escolar. Todos ganharam com a estruturação formal da política pública, que tem muito a ser aperfeiçoada, mas é um ponto de partida fundamental, pensado, debatido, compreendido e legitimado.

A abordagem DPP, nesse contexto, foi utilizada para criar a própria ideia da FIPESP e fez com que cada Instituição participante fizesse uma autorreflexão sobre a sua atuação na questão de inclusão do aluno com deficiência. A partir de então, houve a apresentação oficial da posição das Instituições sobre o tema, com o compartilhamento de visões e de informações, momento em que foi possível desenhar um quadro real dos pontos positivos e das dificuldades existentes. Nesse cenário, a etapa mais complexa foi fomentar o diálogo interinstitucional e construir diretrizes legislativas, respeitando a competência constitucional de cada ator envolvido, de modo a alinhavar uma resolução com bases sólidas a apontar soluções possíveis e adequadas à questão naquele momento, mas com forte

\footnotetext{
${ }^{20}$ Para saber mais ver: Souza, Ana Carolina Ferreira. Fávero, Raquel Fernanda. Silvia Neto, Wilson Levy Braga da. Trabalho apresentado no II Congresso Brasileiro Interdisciplinar nas Defensorias Públicas. Tema: Gestão Democrática: Frente de Instituições Públicas pela Educação. Tese aprovada em 30/11/2017.
} 
tendência a ser eficaz e aprimorada ao longo do tempo pelo processo de retroalimentação positivo. A abordagem DPP forneceu a estrutura necessária para a formalização de políticas públicas duráveis e efetivas ao trabalhar com o problema em suas várias dimensões e interfaces, envolvendo diversos atores.

\section{CONSIDERAÇÕES FINAIS}

A presente reflexão procurou demonstrar a importância metodológica da abordagem DPP no desenvolvimento e condução de políticas públicas de forma consciente e com qualidade por Instituições Jurídicas, nos seguintes aspectos:

(i) Traçar o diagnóstico do perfil institucional: A abordagem DPP propicia que a Instituição Jurídica conheça a sua capacidade administrativa, organize a sua estrutura, compreenda seus limites orçamentários, visando aumentar a eficiência, otimizar fluxos, incentivar boas práticas e aprimorar o controle interno.

Demonstra a importância da inovação, inclusive tecnológica, para possibilitar o melhor planejamento, a curto, médio e longo prazo, a partir de metas possíveis, com modelos jurídicos aprimorados, que abram espaço para a legitimação dos processos decisórios e efetividade nas conquistas dos resultados esperados.

(ii) Organizar dados e redes de informação confiáveis: A abordagem DPP possibilita compreender que cada Instituição Jurídica gera dados exclusivos por força de sua missão constitucional (autoconhecimento). Assim, é necessário investir na formação de uma rede de informações própria, que sejam filtradas e trabalhadas de forma eficaz, de modo a criar pontos de convergência para análise e o manejo de seus dados com credibilidade, tanto para utilização no âmbito interno, como para garantir a transparência de suas ações perante os cidadãos.

Por outro lado, a rede de informações poderá ser utilizada para estimular o desenvolvimento científico, pesquisa, capacitação científica e tecnológica e inovação ${ }^{21}$, o que vai ajudar a aprimorar o próprio sistema de políticas públicas (retroalimentação de inputs e outputs); motivar a abertura de espaços para criar novos conceitos, recomendações, conhecimento do mercado e até a atuação de novos nichos, como think tanks, startups e a relação com o terceiro setor em geral.

(iii) Fomentar o diálogo interinstitucional: a partir do autoconhecimento e da transparência da organização dos dados gerados, passa a ser profícuo o necessário diálogo interinstitucional para criação e aperfeiçoamento das políticas públicas, em especial, as que visam concretizar direitos fundamentais sociais.

O estímulo à articulação e refinamento dos arranjos jurídico-institucionais abre espaço para a criação de uma dinâmica tendente a consolidar a política pública, ou seja, formar um ciclo virtuoso de aprimoramento e estabilidade.

${ }^{21}$ Conforme previsto na Emenda Constitucional n. ${ }^{-}$85, que alterou os artigos 218 e 219 da Constituição Federal e na Lei Federal n. ${ }^{\circ}$ 13.243/16. 


\section{REFERÊNCIAS}

AMARAL, Diogo Freitas do. Curso de Direito Administrativo. Volume II. Lisboa: Almedina, 2001.

ARAÚJO, Edmir Netto de. Curso de Direito Administrativo. São Paulo: Saraiva, 2009.

BUCCI, Maria Paula Dallari. Coutinho, Diogo R. Arranjos jurídico-institucionais da política de inovação tecnológica: uma análise baseada na abordagem de direito e políticas públicas. In: COUTINHO, Diogo R.; FOSS, Maria Carolina; MOUALLEMP, Pedro Salomon B (orgs.). Inovação no Brasil: avanços jurídicos institucionais. São Paulo: Blucher, 2017.

BUCCI, Maria Paula Dallari. Direito Administrativo e Políticas Públicas. Saraiva: São Paulo, 2002.

BUCCI, Maria Paula Dallari. O conceito de política pública em direito. In: BUCCI, Maria Paula Dallari (org.). Políticas Públicas - reflexões sobre e o conceito jurídico. São Paulo: Saraiva, 2006.

DI PIETRO, Maria Sylvia Zanella. Direito Administrativo. São Paulo: Saraiva, 2017.

FREITAS, Juarez de. O controle dos atos administrativos e os princípios fundamentais. 5. Ed. São Paulo: Malheiros, 2013.

FREITAS, Luiz Carlos de. Ximenes: fato surpreendente em SP. AVALIAÇÃO EDUCACIONAL - Blog do Freitas, 2016. Disponível em: $<$ https://avaliacaoeducacional.com/2016/08/24/ximenes-fato-surpreendente-emsp/>. Acesso em: 12 jun.19.

HOOD, Christopher. The tools of Government. London: Macmillan, 1983.

HOWLETT, Michael; RAMESH, M. Perl, Anthony. Política Pública: seus ciclos e subsistemas. Rio de Janeiro: Elsevier, 2013.

ROMANO, Santi. Princípios de Direito Constitucional Geral. São Paulo: Revista dos Tribunais, 1977. 
SÃO PAULO. Secretaria de Educação. Reunião com membros da FIPESP discute políticas públicas em educação especial, 2016. Disponível em: https://www.educacao.sp.gov.br/noticias/reuniao-com-membros-da-fipespdiscute-politicas-publicas-para-alunos-em-educacao-especial/. Acesso em 12 jun. 2019.

SEM AUTOR. Quem somos. Articule, 2019. Disponível em: <http://articule.org.br> Acesso em: 12 ago. 2019.

SOUZA, Celina. Políticas Públicas um revisão literária. Sociologias, ano 8, n. 16, 2006, p. 20-45.

SOUZA, Ana Carolina Ferreira; FÁVERO, Raquel Fernanda. SILVIA NETO, Wilson Levy Braga da. Trabalho apresentado no II Congresso Brasileiro Interdisciplinar nas Defensorias Públicas. Tema: Gestão Democrática: Frente de Instituições Públicas pela Educação. 2017. 